\title{
Gülsün Karamustafa'nın Sanatında Gündelik Nesneye Odaklı Anlatılar
}

\author{
Daily Object-Oriented Narratives in the Point of Art of Gülsün Karamustafa
}

\author{
Mehmet Hasan Demirci* ${ }^{\circledR}$, Cüneyt Kurt* ${ }^{*}$ (1)
}

\section{Öz}

1980'li yıllarda, Türk sanatının tanımı, sınırları ve amacı değişim sürecine girmiş, farklı yaklaşımlarla belirginliğini daha da arttırmıştır. Nitekim bu yıllardan sonra Türk sanatında başlayan yerleştirme odaklı anlayışlarla eserlerde kavramsallaştırma, farklı biçim ve içerik oluşturma ve alternatif nesne vurgusu yaygın hâle gelmiştir. Bu doğrultuda Türk sanatçıların eser üzerine düşünsel ve kavramsal sorgulamaları artmış, nesneye yaklaşım biçimleri eserin oluşmasında etkili olmuştur. Özellikle gündelik nesneden hareketle göç, bellek, kimlik, kültürel ifade, kitsch, popüler kültür imgeleri, cinsiyet gibi başlıkları kendine has anlatımlarıyla sergileyen Gülsün Karamustafa'nın çalışmaları dikkat çekmektedir.

Bu makalede Gülsün Karamustafa'nın çalışmalarında yer alan gündelik nesneye odaklı yerleştirmeler ele alınmış ve bu yerleştirmelerde nesnelerin sanat nesnelerine dönüşümü incelenmiştir. Bu bağlamda nesneye odaklı anlatılardan hareketle makale; Gülsün Karamustafa'nın sanat anlayışı, göç odaklı işlerinde kullanılan gündelik nesneler, kimlik/kitsch odaklı işlerinde kullanılan gündelik nesneler ve cinsiyet odaklı işlerinde kullanılan gündelik nesneler olmak üzere dört alt başlık içermektedir. Makalede incelemeye konu olan veriler, tarama yöntemiyle elde edilmiş, Gülsün Karamustafa'nın 1980 sonrası gündelik nesneye odaklı bazı çalışmaları mercek altına alınmıştır.

\section{Anahtar Kelimeler}

Yerleştirme, Kitsch, Nesne, Gündelik Nesne, Kültürel Ifade

\section{Abstract}

In the 1980s, the definition, boundaries and purpose of Turkish art entered the process of change and increased its prominence with different approaches. After these years, conceptualization, creating different forms and content, and the emphasis on alternative objects have become common in works with installation-oriented understandings that started in Turkish art. In this direction, the intellectual and conceptual inquiries of Turkish artists on the work have increased, and the way they approach the object has been a factor in the creation of the work. The works of Gülsün Karamustafa, who exhibits topics such as migration, memory, identity, cultural expression, kitsch, popular culture images, and gender with her unique expressions, especially based on everyday objects, draws attention.

In this article, the daily object-oriented installations in Gülsün Karamustafa's works are discussed and the transformation of objects into art objects in these installations is examined. In this context, the article is based on object-oriented narratives; Gülsün Karamustafa's understanding of art includes four subheadings: everyday objects used in her migration-oriented

* Sorumlu Yazar: Mehmet Hasan Demirci (Öğr. Gör.), Hatay Mustafa Kemal Üniversitesi, Sanat ve Tasarım Meslek Yüksek Okulu, El Sanatları Bölümü, Hatay, Türkiye. E-posta: mhasandemirci@gmail.com ORCID: 0000-0002-7111-0456

** Cüneyt Kurt (Prof. Dr.), Hatay Mustafa Kemal Üniversitesi, Güzel Sanatlar Fakültesi, Resim Bölümü, Hatay, Türkiye. E-posta: ckurt4@hotmail.com ORCID: 0000-0002-8395-6854

Atıf: Demirci, Mehmet Hasan, Kurt, Cuneyt. “Gülsün Karamustafa'nın Sanatında Gündelik Nesneye Odaklı Anlatılar." Art-Sanat, 17(2022): 83-101. https://doi.org/10.26650/artsanat.2022.17.879592 
works, everyday objects used in her identity/kitsch-focused works, and everyday objects used in her genderoriented works. In the article, the data that is the subject of the study were obtained by scanning method, and some of Gülsün Karamustafa's works focused on everyday objects after 1980 were examined.

Keywords

Installation, Kitsch, Object, Daily Object, Cultural Expression

\section{Extended Summary}

There was intense questioning about what art is or how it should exist in the 1950s and after in Western art. In these art inquiries, which continue beyond traditional understandings, an attitude has developed not only against formal and intellectual but also established rules. With these searches, object-oriented approaches increased in the production of works, conceptual propositions and critical perspectives began to gain weight. Therefore, artists diversified their production of object-oriented works in these periods when the understanding of installation became widespread.

On the other hand, the understanding of installation and object-oriented approaches became intense in Turkish art in the 1980s and later. In this context, Turkish art increased the interaction and interrogation of different disciplines, in this direction, it made the understanding of installation widespread and focused on the object emphasis.

The object-oriented placement understanding that developed with Altan Gürman's use of objects such as cardboard-paper-foam-plastic in his Works has become important for the artists of the Art Definition Society, in the works of the New Trends Exhibition. During these periods, memory-focused everyday objects in Sarkis' exhibition named Çaylak Sokak; Füsun Onur's objects in the garden of the Dolmabahçe Palace in the Dolmabahçe Souvenir installation; the hat object used by Ayşe Erkmen in her work named “J, K \& H” objects in many of Gülsün Karamustafa's works are among the important examples.

The works of Gülsün Karamustafa which are one of the important names of contemporary Turkish art, which she created with daily object-oriented approaches, draws attention in this period. Issues such as migration, memory, identity, cultural elements, kitsch, popular culture images and gender, which Karamustafa extensively deals with in her works, come to the fore with a unique style with their daily use of objects.

Therefore, Karamustafa; with the objects he chooses in his works, creates more intense expressions especially on the reality of migration, identity-cultural elements, kitsch expressions, gender, gender and the place of women in society.

Karamustafa, who is an important breaking point in contemporary Turkish art, focused on subjects with social reflections such as migration, memory, cultural elements 
and kitsch, especially in his 1980 and later works. Artist Karamustafa continued her work with painting in the early years of her art, and later with collages, installation and videos with various materials. Karamustafa, who exhibits human-based approaches throughout her works, has an important place in the subjects she deals with and the relations between the objects she chooses. So many of Gülsün Karamustafa's daily object-oriented works can be said to shed light on the social, cultural memory of the lived periods. Artist Karamustafa also provides opportunities to perceive the social life and contemporary art phenomenon of that period, especially with the works he created in 1980 and after.

Objects such as quilts, rugs, fabrics, vests and spoons chosen by Gülsün Karamustafa in her migration-oriented works are mainly based on the themes of migration and identity. Migration and identity-themed works, which the artist emphasizes with various everyday objects, are also local and universal dynamics fed by his own life. Therefore, the subject of migration, which the artist expresses concerning objects in his arrangements, is in an intense relationship. Karamustafa's artistic use of daily objects such as satin quilts and spoons, which are cultural expressions of rural identity, took place as a powerful expression in Turkey, especially in the 1980s.

The jar chosen by Karamustafa in her identity and cultural identity studies, satin fabrics with a kitsch expression, tapestries, plexiglass grasses, artificial flowers, on the other hand, offer a periodical and mass expression. The artist's emphasis on arabesque and kitsch, which broke out in the 1980s, carries an ironic and questioning expression with the objects he chooses. Karamustafa's daily objects, especially in Eastern and Western cultures, provide a social/cultural reading of the lived period.

Objects such as mannequins and ribbons, which Gülsün Karamustafa uses in her gender and gender narratives, examines identity questioning and women's life in society. In particular, the ribbon material, beyond being an object, questions the status of women in society and the way they occupy a place and serves as a memory.

As a result, Gülsün Karamustafa's object-oriented installation take place in a structure that predominates social, social, and cultural expressions. The objects used by the artist in his works are from life and express a cross-section and period of life. The daily objects that the artist Karamustafa uses in her works are in a way that depicts a history, period, event or mass, and is also an analysis tool that reveals the facts and views in the background of culture, memory, in short, social lifestyle. The objects that makeup almost all Karamustafa's work, carry a strong conceptualization dimension with form and content and load a representation and a story, and leave permanent references at the point of the flow of art into daily life. 


\section{Giriş}

Batı sanatı 1950'li yıllardan itibaren biçimsel, düşünsel ve kavramsal bağlamda önemli ölçüde sorgulamalar oluşturmuştur. Bu doğrultuda sanatçılar yerleşik kurallara karşı tavırlarını çeşitlendirmiş, eserlerinde eleştirel bakışlarını arttırmıştır. Dünya sanatına yön veren bu önermeler 1950'li yıllar ve sonrasında Türk sanat ortamına da düşünsel ve uygulama bağlamında yoğun imkânlar katmıştır. Nitekim Türk sanatında özellikle 1950-1980'li yıllarda sosyo-ekonomik yapının ve teknolojinin gelişmesi ile sanatçıların özgün üslupları ve Batı odaklı yaklaşımları hız kazanmıştır.

Bu bağlamda Türk sanatında birçok sanatçı, eserlerinde yerleştirme odaklı yaklaşımlarla alternatif nesnelere yönelmiş ve kavramsallaştırma anlayışını gütmüştür. Nesnenin Altan Gürman'ın eserlerinde başat rol oynamaya başlamasının Türk sanatına yön veren birçok sanat üretimine kaynaklık ettiği söylenebilir. Sanat Tanımı Topluluğu ${ }^{1}$ sanatçılarında, Yeni Eğilimler Sergisi'nde ${ }^{2}$ ve daha birçok sanatçıda önemli rol oynayan nesne, yeni anlatımlar kazanmıştır. Örneklemek gerekirse bu dönemde nesne, Sarkis Zabunyan'ın 1986 tarihindeki “Çaylak Sokak” adlı sergisinde bellek görevi görmüş, Füsun Onur'un Dolmabahçe Hatırası ve daha başka yerleştirmelerinde anılarla yüklü olmuş, Ayşe Erkmen'de başat rol oynayarak mekânın kendisi hâline gelmiş, Gülsün Karamustafa'nın birçok çalışmasında ise yeni bağlamlar kazanarak toplumsal, sosyal, kültürel katmanlar oluşturmuştur.

Bu bağlamda yerleştirmelerinde özellikle gündelik nesne üzerinden yaklaşımlar sergileyen Gülsün Karamustafa'nın nesneyi kendi içindeki özgünlüğünden hareketle maddesel gerçeğinden kopararak sanat eserine dönüştüren tavrı dikkat çekmektedir. Dolayısıyla bu çalışma, Gülsün Karamustafa'nın gündelik nesneye odaklı bazı yerleştirmelerini konu edinmektedir.

Karamustafa, disiplinler arası yaklaşımlarla çalışan sanatçılar arasındadır. Çağdaş sanatın farklı medyumlarıyla yaşadığı dönemin toplumsal yapısını, sosyal ve kültürel yansımalarını kendi yaşantısını da katarak sanatına konu edinen Karamustafa, özellikle gündelik nesneler üzerinden yeni anlatım biçimleri oluşturmuştur. Karamustafa göç, kimlik, bellek, kitsch, arabesk, cinsiyet gibi başlıkları sanatına konu edinerek eser, nesne ve izleyici arasındaki bağlamı sıkılaştırmıştır.

\section{Gülsün Karamustafa'nın Sanat Anlayışı}

1946 yılında Ankara'da doğan Gülsün Karamustafa, 1963-1969 yılları arasında İstanbul Devlet Güzel Sanatlar Akademisi’nde Bedri Rahmi Eyüboğlu'nun atölyesinde

1 Sanat Tanımı Topluluğu, 1978 yılında Şükrü Aysan, Ahmet Öktem ve Serhat Kiraz’ın öncülüğünde kurulan, Kavramsal Sanat'ın doğasını, yapısını araştıran bir sanat topluluğudur.

2 Yeni Eğilimler Sergisi, 1977 yılından itibaren Türk plastik sanatlar anlayışına yeni bir ivme kazandırmış, çağdaş Türk sanatının sınırlarını genişletmesinde ve sanatçıların yeni biçim ve içerikler kazanmasında önemli bir yer tutmuştur. 1977 yılından itibaren düzenli olarak iki yılda bir, toplam altı sergi gerçekleştirmiş olan Yeni Eğilimler etkinlikleri, uzun bir ara sonrası, yedinci ve son sergisini 1994 tarihinde açmıştır. 
klasik resim eğitimini tamamlamıştır. Karamustafa, 1980’li yıllara kadar resim alanında çalışmış, sonraki yıllarda ise çağdaş sanatın çeşitli biçimlerini kullanarak farklı disiplinlerde sanat üretimleri yapmaya başlamıştır. 1980’li yılların siyasi çalkantıları nedeniyle üniversitedeki görevinden ayrılan Karamustafa, "Edebiyat dergilerine yaptığı illüstrasyonlarla geçimini sağlamaya çalışmıştır. Başarılı bir ressam olmasına rağmen seksenli yılların sonunda resim yapmayı bırakmış ve diğer malzemelerin sunduğu yeni ifade olanaklarını kullanmaya başlamıştır". 3 Sanatında ağırlıklı olarak gündelik nesneler üzerinden değişik sunum şekillerini kullanan Karamustafa, hem dışa dönük toplumsal belleğe odaklı hem de kendi belleğine dönük yaklaşımlar sergilemiştir.

1980’li yıllardan itibaren Türk sanatının mihenk taşlarından olan Karamustafa’nın sanatı, yaşanan dönemin bir anlatıcısı olarak görülebilir. Çiğdem Sağır'ın ifadesiyle; "Bu dönemde Karamustafa çağdaş Türk sanatında önemli bir kırılma noktasıdır. Karamustafa'nın hem işleri hem de toplumsal kimliği ve deneyimleri seksenler Türkiye'sinde çağdaş sanat olgusunu birçok katmanlarıyla anlamamıza yardımcı olacaktır'. ${ }^{4}$ Karamustafa, yaşadığ 1 dönemin özellikle göç, kimlik, kültür, kitsch ve cinsiyet konularına seçtiği nesneler üzerinden yaklaşır. Karamustafa'nın ağırlıklı olarak yerleştirme odaklı çalışmalarında seçtiği nesneler toplumsal bir ifadenin ve kültürel yansımanın izlerini taşımakta, sanat ve nesne ilişkisinin derin olanaklarını oluşturmaktadır.

Karamustafa'nın çalışmalarında seçtiği objeler her ne kadar gündelik hayatın parçalarını oluştursa da onlar bir dönemin, yaşam tarzının, kırsalın, kentin yansımalarını birçok açıdan içermektedir. Öyle ki nesnelerin yoğun anlatımlar içermesi Karamustafa'nın sanat ve nesne arasındaki bağlamını güçlü kurmasından kaynaklanmaktadır. Onun yaklaşımlarıyla gündelik yaşamın parçası olan nesneler, bağlamından koparılan anlam yüklü ve temsil gücü yüksek ifadelere dönüşmektedirler. Karamustafa, nesneye yönelik bağını Levent Çalıkoğlu ile söyleşisinde; “(...) Bunlar çevremde bulduğum, gördüğüm, sosyal hayatın içinden birtakım objelerdi ve bunlarla yeniden sanatımı üretmeye başladım." ş̧eklinde ifade etmiştir. Karamustafa’nın nesne tercihleri ağırlıklı olarak sorun edindiği göç, kimlik, kitsch ve toplumsal cinsiyet temasından kaynaklı olmuştur. Dolayısıyla Karamustafa'nın çalışmaları sanatın günlük hayata akması noktasında kalıcı referanslar bırakmaktadır.

\section{Göç Odaklı İşlerinde Kullanılan Gündelik Nesneler}

Göç, yerel ve küresel bağlamda sosyolojik, psikolojik, kültürel, ekonomik, politik boyutları olan, önemli ölçüde etkiler barındıran bir olgudur. Dolayısıyla göç, birçok

3 Neslihan Kıyar ve Serdar Kul, "Sanat Tanımı Topluluğu ve Bağımsız Bir Çağdaş: Gülsün Karamustafa” İdil, 58 (2019): 783-791.

4 Çiğdem Sağır, “Gülsün Karamustafa”. Seksenlerde Türkiye'de Çağdaş Sanat: Yeni Açılımlar, Ed. İpek Duben ve Esra Yıldız (İstanbul: İstanbul Bilgi Üniversitesi Yayınları, 2008), 159.

5 Levent Çalıkoğlu, “Gülsün Karamustafa” Çağdaş Sanat Konuşmaları 3, 90’lı Yıllarda Türkiye'de Çağdaş Sanat (İstanbul: Yapı Kredi Yayınları. 2008), 55. 
disiplinde olduğu gibi sanat disiplinleri arasında da önemli yer tutmaktadır. Sanat alanında daha çok kimlik üzerinde yansımalar oluşturan göç; yersiz yurtsuzlaşma, ötekileşme, kabul ettirme, kültür, bellek, melezleşme ve arabesk gibi temalarla işlenmektedir. Solmaz Bunulday Hasgüler, “1980’ler sonrası yaşanan iç ve dış göç etkilerinin de sanatçıların üretimlerine yoğun bir şekilde yansıdığını belirtmiştir". ${ }^{6}$ Özellikle köyden kente göç doğrultusunda yaşanan olumsuz durumların ortaya ç1kardığı kimlik çatışmaları, ötekileşme, melez kültür ya da arabesk vurguları sanatçı eserlerinde s1kça işlenmiştir.

Gülsün Karamustafa'nın çalışmalarında da göç ifadeleri yoğun şekilde yer almaktadır. Karamustafa, “1980'lerde Anadolu'dan özellikle Balkanlar'dan ve Rusya'dan İstanbul'a göç eden insanların yaşadığı yerleri inceler. Türkiye' deki toplumsal yapının hızlı bir şekilde değiştiği bu dönemde göç, kimlik, yerinden yurdundan edilme sürecini kendine özgü bir dille sanatının konusu haline getirir". ${ }^{7}$ Karamustafa'nın, sanatında özellikle seçtiği yorgan, kilim, örtü, kumaş, kaşık, yelek gibi nesneler ağırlıklı olarak göç ve kimlik teması üzerine kuruludur. Sanatçı, göç odaklı nesnelerle ilgili çıkış noktasını, “(...)80’li yılların köyden kente göçle birlikte hızlı bir değişim geçiren büyük şehirlerdeki melez gelişimi gözlemlemeye başladım ve bu duruma ilişkin, çevremde var olan objelerin gücünü hissettim..." ş̧eklinde belirtmiştir. Sanatçının çalışmalarındaki bu nesneler gündelik hayatın bir parçası olmakla birlikte topluma dair belleği okuma görevi görmüştür. Bu bağlamda sanatçının yerleştirmelerinde nesneler üzerinden dokunduğu göç mevzusu yerel, ulusal hatta evrensel bir ilişkilendirme içerisindedir.

Sanatçı'nın özellikle “Anı-Bellek” sergisine hazırladığı Kuryeler isimli çalışmasındaki seçtiği yelekler göçü temsil eden sanat nesnelerine dönüşmüştür (G. 1). Karamustafa, Kuryeler çalışmasının oluşumu için "Çıkış noktası anneannemin anlattığı kendi geçmişimden bir hikâyeye dayanıyordu. 'Sınırları Geçerken Bizim İçin Önemli Olanları Çocuk Yeleklerinin İçine Dikerek Saklıyorduk' "' ifadesini kullanmıştır. Karamustafa, geçmişinin izlerini taşıyan Kuryeler yerleştirmesi için kumaştan diktirdiği üç yeleği sergi salonuna giyilmiş hissini oluşturarak yerleştirmiştir. Barbara Heinrich’e göre;

"İzleyici dikili bölmelere gizlenmiş şeylerin varlığını sezebiliyor ama tam olarak ne olduklarını okuyamıyor, onlara dokunamıyordu. Eski Yugoslavya'da yaşanan göç trajedisinin duygusal ağırlığı altında gerçekleşen bu çalışma, sanatçının (kendisi de göçmen olan) büyükannesinin göç sırasında taşınan değerli malların çocukların üzerlerindeki yeleklere saklandığına dair anlattığ hikayelere dayanıyor". ${ }^{10}$

6 Solmaz Bunulday Hasgüler, Türkiye'de Sanat Üretimi 1975-2005 (İstanbul: Parşömen Yayıncılık, 2013), 134.

7 Mehmet Akif Kaplan, "Çağdaş Türk Sanatında Göç, Yersizyurtsuzlaşma Olgusunun Gülsün Karamustafa Sanat Çalışmaları Üzerinden İncelenmesi," Sosyal Bilimler Dergisi / The Journal of Social Science 29 (2018), 317.

8 Çalıkoğlu, "Gülsün Karamustafa" Çağdaş Sanat Konuşmaları 3, 90'll Yıllarda Türkiye'de Çağdaş Sanat, 73.

9 Çalıkoğlu, "Gülsün Karamustafa" Çağdaş Sanat Konuşmaları 3, 90'lı Yıllarda Türkiye'de Çağdaş Sanat, 63.

10 Barbara Heinrich, Gülsün Karamustafa: Güllerim Tahayyüllerim, (İstanbul: Yapı Kredi Kültür Sanat Yayınlar1, 2007), 53-55. 


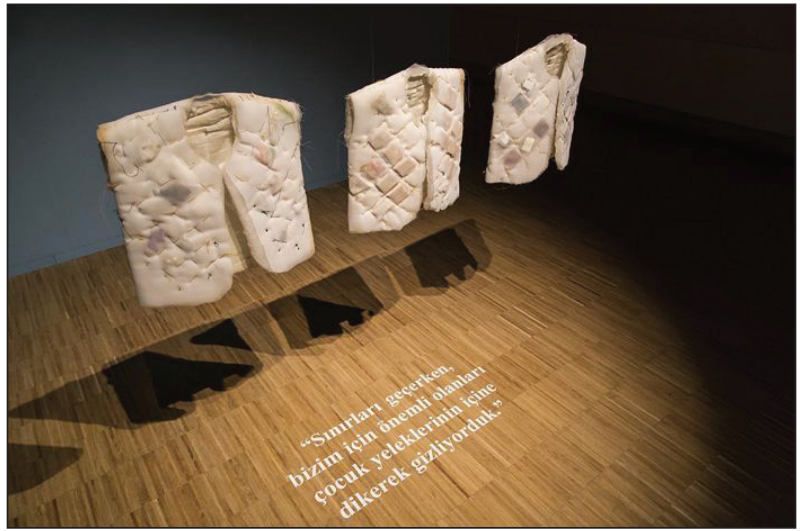

G. 1: Gülsün Karamustafa, Kuryeler, 1991. (https://saltonline.org/tr/664/atolye-ipucu)

Karamustafa, Kuryeler (1991) isimli çalışmasında Balkan Savaşı, Kafkas Savaşı ve Birinci Dünya Savaşı'nın sözlü tarihinden alınmış anektodları küçük kâğıtlar üzerine yazarak, şeffaf, sargı bezi benzeri kumaştan yapılmış çocuk yeleklerinin içine dikmiştir. ${ }^{11}$ Sanatçı, Kuryeler işini 93 Harbi’nde Bulgaristan'dan Türkiye’ye göç etmek zorunda kalan büyük annesinin sözünden hareketle gerçekleştirir ve dolayısıyla bu söz söylendiği atmosferin izlerini taşıyarak bir metafor hâline gelir. Sanatçı elle dikilmiş üç tane çocuk yeleğiyle göçü simgeleştirmiş, izleyiciye bu atmosferi duyumsatmıştır. Bu çalışmada kültürel bir çözümleme ve araştırmaya dönüşen yelekler izleyiciye yaşam izlerini hissettiren, tarihe tanıklık eden, sınırları aşan evrensel anlatım sağlamıştır. Duygu Sabancılar'a göre “Gülsün Karamustafa İstanbul Artnews'in Ocak 2015'de yayımlanan sayısında Özlem Altunok ile gerçekleştirdiği söyleşisinde kendisi için önemli saydığı nesnelerin; bazı tekstler, notlar, babasının el yazısıyla yazdığı mektuplar, birtakım film artıkları ve objeler olduğunu ve yeleklerin içine dikilen tüm bu önemli nesnelerin görülebilir ama dokunulmaz olmalarını istediğinden bahsetmiştir". ${ }^{12}$ Dolayısıyla Karamustafa'nın sanatında göç vurgusu seçtiği nesnelerle daha etkin hâle gelmiştir. Çünkü göç ile yerinden olma duygusu sanatçının da yaşamış olduğu bir travmadır ve Karamustafa, bu durumu tarihsel verilerle, özenle seçtiği nesnelerle daha okunur duruma getirmiştir. Karamustafa, "Kendini dolaşımda, göç eden sanatçı olarak tanımlar. Karamustafa seçtiği göç konusu gibi uluslararası arenada sergiden sergiye işleriyle birlikte göç eden bir yaşantının içinde bulur kendini. Sanatçı, çalışmalarında göç mağduru insanların trajedisini, sınır aşırı küresel ekonomi politikalarının insanları yerinden ettiğini gözler önüne serer". ${ }^{13}$

11 Sağır, "Gülsün Karamustafa”. Seksenlerde Türkiye’de Çăgdaş Sanat: Yeni Açılımlar, 172.

12 Duygu Sabancılar, "Bireysel ve Toplumsal Hafızanın Sanat Eserlerinde Kıyafet Aracılığı ile Kurgulanması Gülsün Karamustafa ve Gülçin Aksoy”, Sanat ve Tasarım Dergisi 18 (2016): 133-145.

13 Kaplan, "Çağdaş Türk Sanatında Göç, Yersizyurtsuzlaşma Olgusunun Gülsün Karamustafa Sanat Çalışmaları Üzerinden İncelenmesi,” 323. 
Karamustafa'nın sanatında göç, sadece yerinden edilme değil ayrıca Türkiye'de özellikle 1980'li yıllarda köyden kente doğru yoğun yaşanan akışı da ifade etmiştir. Kırsaldaki yaşamın kente akması ve kırsal kimliğin kopmadan kente yerleşmeye çalışması gibi durumlar Karamustafa'nın çalışmalarında güçlü bir anlatım olarak karşımıza çıkmaktadır. Karamustafa, seçtiği gündelik nesnelerle oluşturduğu ve 2014 yılında Salt Beyoğlu’nda "Vadedilmiş Bir Sergi” başlığıyla açtığı sergi, göç olgusunu birçok yönüyle ortaya koymuştur. "Göç, kimlik, bellek, toplumsal cinsiyet gibi birçok farklı konuya temas eden sergi, sanatçının kırk yılı aşan sanat pratiklerini ortaya koymakta ve sadece Türkiye'de değil aynı zamanda uluslararası düzeyde de yapılmış en kapsamlı sergi olma özelliğini taşımaktadır."14 Toplumsal yaşama ait birçok dokuyu içinde barındıran "Vadedilmiş Bir Sergi”, göçebe yaşantısını, göçebe kavramını tüm benliğiyle ortaya koyar biçimdedir. Karamustafa’nın sergideki çalışmalarından birisi olan ve 1992'de 3.İstanbul Bienali'nde de yer alan Mistik Nakliye (G. 2) isimli yerleştirmesinde seçmiş olduğu yorgan bir dönemin yaşam izlerine ait güçlü hikâyeleri barındırır. Selen Sarığlu'nun ifadesiyle Mistik Nakliye; “Gülsün Karamustafa'nın 1980’lerde yerel bağlamda ele aldığı göç olgusunu daha küresel boyutları ile tartışmaya açtı̆̆ 1 ilk iştir"'15

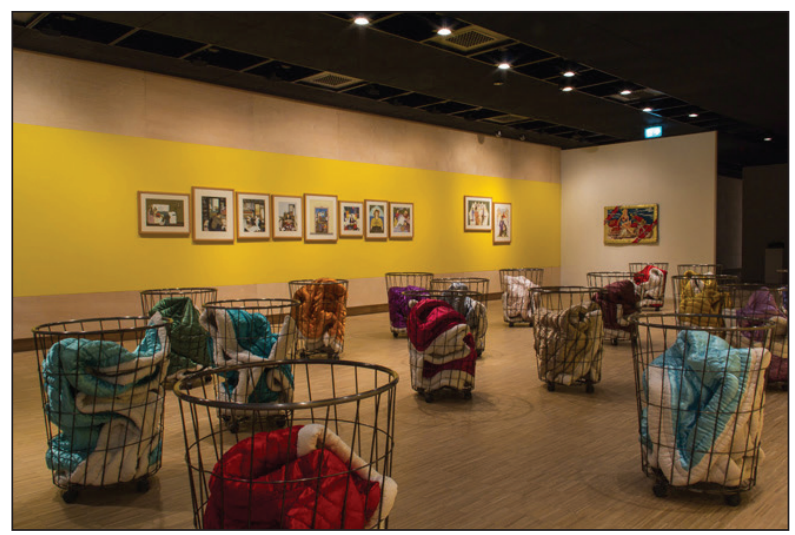

G. 2: Gülsün Karamustafa, Mistik Nakliye, Vadedilmiş Bir Sergi (10 Eylül 2013-5 Ocak 2014)

(http://www.sanatatak.com/view/saltta-bahar-vadedilmis-bir-sergiyle-devam-ediyor)

Sanatçı, bu çalışmada 1980-1990’lı yıllara kadar çok kullanılan geleneksel saten yorganları değişik renklerde hazırlayarak onları tekerlekli metal sepetlerin içini dolduracak şekilde yerleştirmiştir. Saten yorganların sarmalanmış şekilde sepetin içinde yer alması güzergahı belli olmayan gizemli göç yolculuğunun her an başlayacağını ifade eder şekildedir. Nitekim Karamustafa’nın diğer birçok işinde olduğu gibi Mistik Nakliye eserinde de merkeze alınan şey nesnenin kendisidir. Hasan Bülent

14 M. Kemal İz, “Salt’ta Bahar, 'Vadedilmiş Bir Sergi’yle Devam Ediyor” (18 Eylül, 2013) http://www.sanatatak.com, erişim 20 Aralık 2021.

15 Selen Sarıoğlu, “Gülsün Karamustafa: Sanatçı Kişiliği ve Yapıtları” (Yüksek Lisans tezi, Mimar Sinan Güzel Sanatlar Üniversitesi, 2007), 28. 
Kahraman'a göre; “Mistik kavramı açık bir biçimde işin yorganlarla ilgili kısmına göndermede bulunuyordu. Yorganın Anadolu insanı için ifade ettiği anlamlar bu kavramla çağrıştırılıyor ve yeniden üretiliyordu. Nakliye ise gene Anadolu insanının bir türlü bitiremediği göç dalgalarına işaret ediyordu. Anadolu'dan gelmiş milyonlarca insan sırtında yorganını taşımıştı". ${ }^{16}$ Kültürel bir imge olan saten yorganlar, eskiden çeyiz süsü, sünnet yatağının süsü gibi sosyal mesajları veren bir nitelik taşırken, Mistik Nakliye yerleştirmesinde kırsaldan kente göçü ifade etmiştir. Karamustafa için yorgan yerel bir imge gibi dursa da aslında evrensel anlatıma da bürünmüştür. Öyle ki göç, yaşayan birçok toplumun mevzusudur ve Mistik Nakliye bu anlatımı gündelik nesnelerle dokunaklı bir şekilde aktarmaktadır.

Karamustafa'nın diğer çalışmalarında da dokunaklı göç ayrıntılarını görmek mümkündür. Vatan Doğduğun Değil, Doyduğun Yerdir (G. 3) çalışmasında sarmalanmış kaşıklar göçe tanıklık etmektedir. Sergide üç kaşık, beyaz sargı bezinin içinde sarmalanmış ve yemek masası örtüsünü andıran beyaz kumaşın üstüne yerleştirilerek göçü temsil eden bir sanat nesnesine dönüşmüştür. Çalışmada biçimsel olarak birbirinden farklı olan üç kaşı̆̆ın biri tek diğer ikisi ise çift sarmalanmıştır. Kaşıkların ikiye bir şekilde sarmalanması aslında merak uyandırmaktadır. Mutfağın aracı olmaktan çıkan bu kaşıklar belki de aynı ya da farklı coğrafyalardan göç eden insanların hikayesini bir arada tutmaktadir.

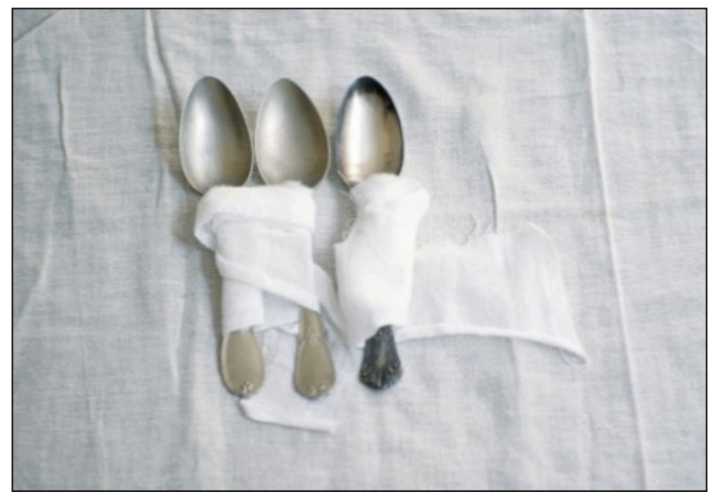

G. 3: Gülsün Karamustafa, Vatan Doğduğun Değil Doyduğun Yerdir, 1994 (https://archives.saltresearch.org/handle/123456789/189732)

Karamustafa’nın Vatan Doğduğun Değil, Doyduğun Yerdir yerleştirmesinde sarıp sarmaladığ1 üç kaşık nesnesi, göç olgusunu biçimsel ve kavramsal bağlamda ortaya koymuştur. Nitekim göç, insanların yaşamsal malzemelerini, günlük kullanım eşyalarını, anılarını, hayallerini yani hayatı tüm katmanlarıyla taşıdıkları bir olgudur. Karamustafa, Cansu Çelebi Erol'un ifadesiyle; “Köyden kente doğru yönelen insan hareketlerinin neden olduğu travmatik yaşantıları, göçmenlerin dramını, göçebe ya- 
şayan insanların görüntülerini filmlerle, kitsch malzemelerle görünür kılarken eser, mekân ve eşyayı eklektik bir yapıyla bir araya getirmiştir". ${ }^{17}$ Karamustafa, göçü deneyimlemiş bir sanatçı olarak çalışmalarına taşımıştır.

\section{Kimlik ve Kitsch Odakıı İşlerinde Kullanılan Gündelik Nesneler}

1980'li yıllardan itibaren Türkiye'de giderek yoğunlaşan köyden kente göç, yaşam olgusunda melez, yoz, pop kültürü, kitsch $^{18}$ ve arabesk gibi ifadeleri yaygınlaştırmıştır. $\mathrm{Bu}$ dönemde resim, kolaj, fotoğraf, video, yerleştirme gibi sanatın çeşitli formlarını çoğulcu yaklaşımla sergileyen Gülsün Karamustafa, eserlerini çoğunlukla gündelik nesneler üzerinden devam ettirir. Sanatçının kırsaldan kente göç ya da 1980'li yıllarda patlak veren arabesk, kitsch vurgusu seçilen nesnelerle ironik, dönemsel ve sorgulayıcı bir anlatım taşımıştır. Özellikle tekstil malzemelerinden yaptığı kolajlarla sosyal ve kültürel yozlaşmalara, yoz beğenilere değinen Karamustafa, seçtiği nesnelerle sembolik ve düşünsel anlatımlar sağlamıştır. Karamustafa'nın Elvisli Seccade (G. 4) isimli çalışmasında kullandığı altın varaklı kumaş ve üzerindeki resim nesnesi, bir dönem okumasını sağlarken ironik bir durum ortaya koyar. Çiğdem Sağır'a göre, "Bu ironik anlatımda, dinsel nesne içinde yeni nesneleri barındırarak farklı bir kutsallığa gönderme yapar". ${ }^{19}$

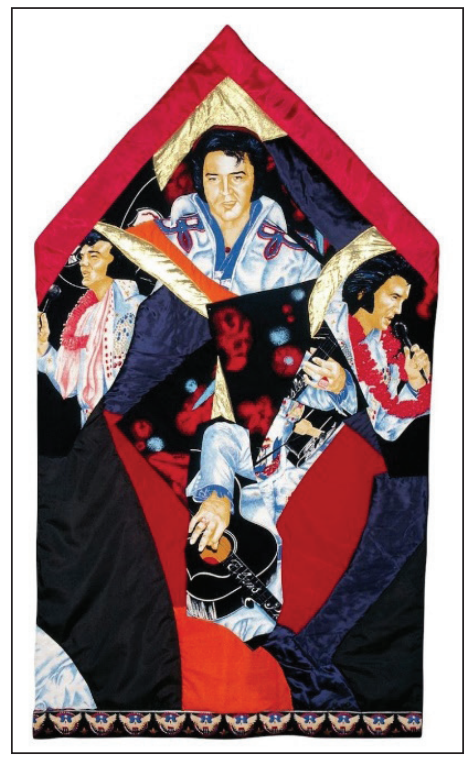

G. 4: Gülsün Karamustafa, Elvisli Seccade, Duvar Halıs1 (180x105cm),1986 (https://saltonline.org/tr/2081/duskun-ikona)

17 Cansu Çelebi Erol, “Göçün Öteki Yüzü, Türkiye Çağdaş, Sanatında Göç, Olgusu”, Ulakbilge 47 (2020): 400-407.

18 Kitsch: "Seçkinlerin beğenmediği, kitlelerin de kopamadı̆̆ı sanat tarzı. Seçin beğeniye hitap edemeyen ama toplumun alt kültüründen insanları etkileyen ve estetik açıdan bayağı, değersiz olan ürün”. Bk. Nimet Keser. Sanat Sözlüğ̈̈̈ (İstanbul: Ütopya Yayınevi, 2009), 184

19 Çiğdem Sağır, “1980 Sonrası Türkiye’deki Sanatın Dönüşümünde Gülsün Karamustafa’nın Yeri” (Yüksek Lisans Tezi, İstanbul Teknik Üniversitesi, 2005), 35. 
Karamustafa, bu dönemsel anlatımda pop ikonu Elvis Presley'in saten kumaş malzemeleriyle oluşturduğu bazı resimlerini kolaj mantığında yerleştirerek duvar halısı ve kitsch ifadeyle sanatsal düzeye ulaştırmıştır.

Bu çalışmasında Karamustafa, Sağır’ın deyişiyle; “(...) Kitsch nesne kullanımı Karamustafa için artık bir tercihten öte bir zorunluluk gibidir. Tekstili malzeme olarak kullandığı işlerinden Elvisli Seccade'de (1986) popülist bir imgeye dönüşen Elvis Presley resimleri ile dinsel objeleri, altın varaklı bir seccade kumaşı üzerinde bir araya getirerek alaylı ve ironik bir dil kullanır". ${ }^{20}$ Karamustafa'nın bir kitlenin anlatımına bürünen Elvisli Seccadesi'nde Elvis Presley resimleri ve dinsel nesne olan seccadenin bir aradalığı zıtlık barındırmanın yanında o dönemde popüler kimliğin oluşturduğu Presley’e olan yaklaşımın yoğunluğunu gözler önüne sermiştir. Dolayısıyla Karamustafa'nın imgeleri aslında Doğu-Batı nezdinde gelişerek kültürel motiflerde karşılık bulmuş ve bir dönemin izlerini taşımıştır.

Sanatçının Kavanozda Venüs (G. 5) çalışması yine benzer bir özellikte olup, Batılı imgenin Doğulu bir imgeyle karşılık bulmuş hâlidir. Bu çalışmada, gündelik yaşamın parçası olan ve ev hanımları ile özdeşleştirilen kavanoz, kadının kimliğini, statüsünü daha belirgin kılan bir imge şeklini almıştır. Ancak Venüs'ün kavanozun içinde barınması belki de bir koruma hâlini de ortaya koymaktadır. Yani kavanoz burada bir koruma görevinde de bulunmaktadır. Venüs karakteri, kavanozun içinde kendini koruma altına alma duygusuyla yer etmiştir. Çalışmada, kavanoz ve Batı' daki bir kültür/imge olan Venüs karakteri iç içe yer almış ve kültürlerarası bir imgeye dönüşerek evrensel anlama bürünmüştür.

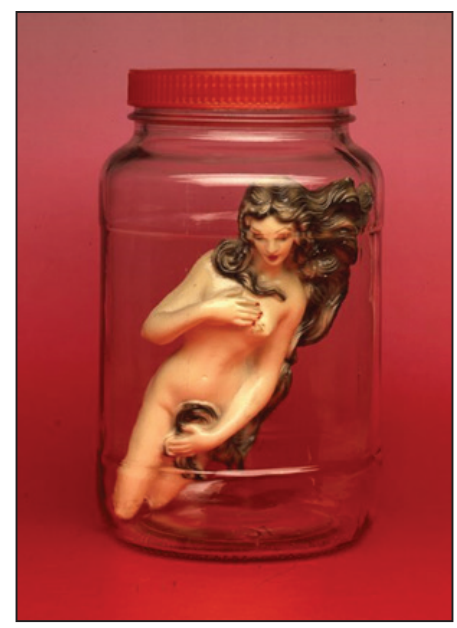

G. 5: Gülsün Karamustafa, Kavanozda Venüs, 1988, 'Vadedilmiş Bir Sergi' Salt Beyoğlu, Salt Galata.

(https://saltonline.org/tr/616/vadedilmis-bir-sergi)

20 Sağır, "Gülsün Karamustafa”, Seksenlerde Türkiye'de Çă̆daş Sanat: Yeni Açılımlar, 165. 
Gülsün Karamustafa'nın nesneye olan yaklaşımları görüldüğü üzere yaşama odaklı bir şekilde gelişme göstermiştir. Onun seçtiği nesneler gündelik hayatın rutin parçaları iken, bir kimlikle, kitleyle ya da durumla özdeşleşerek temsiliyet hâline gelmekte, yaşama dair gerçek durumların okunmasını sağlamaktadır. Kavanozda Venüs adlı çalışmada sanat imgesi ve mitolojik karakter olan Venüs'ün Doğu toplumunda kadınla özdeş hâle gelen kavanoz nesnesiyle olan bir aradalığı Karamustafa'nın kendi kültüründeki kadının yerinin sorgulamasını yapar niteliktedir.

Sanatçının işlerine bakıldığında çok belirgin olan kendi yaşamının, yaklaşımlarının ve bulunduğu toplumla olan etkileşimlerinin izlerini görmek mümkündür. Karamustafa'nın bazı çalışmalarında seçtiği gündelik kıyafetler, süs eşyaları gibi kültürel ifadeler, hazır yapım nesneleriyle bir araya gelmekte ve kitsch nitelik oluşturmaktadır. Karamustafa'nın Abide I (1987) (G. 6) ve Abide II (1988) (G. 7) yerleştirmeleri bu duruma örnek verilebilir. Abide I yerleştirmesinde kaide üzerine örtülmüş kırmızı renkli kumaş, onun üstünde pembe ve altın renklerle süslenen bir vazo ve vazonun içinde plastik malzemelerden oluşan çiçekler yer almaktadır. Loş ve kutsayıcı bir ortamda sergilenen Abide I yerleştirmesinde vazo, tepeden alta doğru sarkan bir tül ile korunaklı hâle getirilmiştir. "Abide 1" işi enstalasyon açısından oldukça ilginç durmaktadır. Gündelik hayatta sıkça salonlarda kullanılan sehpa tüller ile örtülmüş ve sergi salonlarında eserleri daha estetiksel değer kapma açısından kullanılan 1şıklar ile sehpa anlamsal olarak başka bir boyuta taşınmıştır". ${ }^{21}$ Abide II yerleştirmesi ise yine Abide I yerleştirmesiyle benzer bir ortam ve malzemelerle sergilenmiştir. Bir kutu ile korunaklı yapıya bürünen Abide II yerleştirmesinde yine loş bir 1ş1k, plastik demet çiçek ve iki renkli dantelli çocuk elbisesi yer almıştır. Abide II çalışmasının yerleşimi ve malzemeleri üzerine Barbara Heinrich şu ifadelerde bulunmuştur;

\footnotetext{
"Pleksiglas malzemeyle yapılmış dar ve yüksek bir kutu içinde yumuşak kumaşla dokunmuş biri pembe biri açık mavi dantelli iki çocuk elbisesi yerleştirilmişti; aralarına konan ışık kaynağı her ikisini de içeriden aydınlatıyordu. Kıyafetlerin üst tarafinda parlak pembe renkte bir demet plastik çiçek yer alyyordu. Kutunun altında yer alan kare şeklindeki yapay çimden altlık, sergi salonun (17. Yüzyıldan kalma bir Osmanlı köşkü) tabanını kaplayan kırmızı halıyla bir tezatlık oluşturuyordu". 22
}

21 Kıyar ve Kul, "Sanat Tanımı Topluluğu ve Bağımsız Bir Çăgdaş: Gülsün Karamustafa”, 788, 22 Heinrich, Gülsün Karamustafa: Güllerim Tahayyüllerim, 50. 


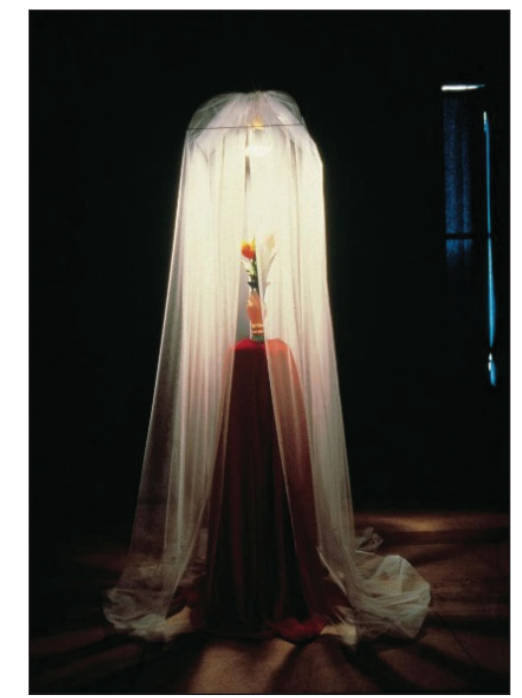

G. 6: Gülsün Karamustafa, Abide 1, 1987

4. Öncü Türk Sanatından Bir Kesit, İstanbul: Atatürk Kültür Merkezi Galerisi, 1987 (https://saltonline.org/tr/2007/gulsun-karamustafa-ile-salt-arastirmadaki-arsivi-uzerine)

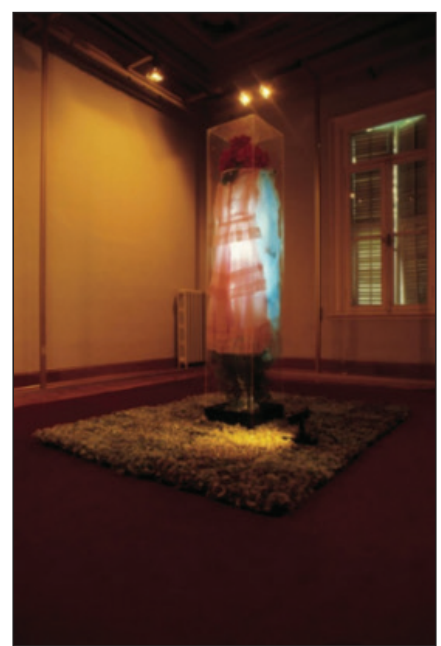

G. 7: Gülsün Karamustafa, Abide 2, 1988, 5. Öncü Türk Sanatından Bir Kesit, İstanbul: Hareket Köşkü, 1988,

(https://saltonline.org/tr/2007/gulsun-karamustafa-ile-salt-arastirmadaki-arsivi-uzerine)

Yerleştirmede zeminde plastikten oluşan çimenlerin oluşturduğu halı, halının ortasında ise pleksiglastan oluşan bir fanus, fanusun içinde ise 1 ş1k ve giyilen pembe-mavi elbise nesnesi yer almaktadır. 1988 tarihli “5. Öncü Türk Sanatından Bir Kesit” isimli sergide Karamustafa’nın Hareket Köşkü’ndeki Abide 2 çalışması aslında mekâna odaklı yapıda gelişmiştir. Karamustafa, Selen Sarığlu’nun deyişiyle; “1988'de 1. Hareket Köşkü’nde gerçekleştirilen “5. Öncü Türk Sanatından Bir Kesit” sergisine 
mekânın ruhuyla tam anlamıyla bir tezat ve gerilim oluşturan ilk site specific (mekâna özel) enstalasyonu-Abide II/Monument II (1988) ile katılır”. ${ }^{23}$ Çalışmada 1şığın nesneler üzerindeki kutsayıc1-otantik etkisi hatta mekânı kuşatan yapısı kültürel bir sorgulamayı beraberinde getirmiştir. Dolayısıyla yerleştirmede kullanılan gündelik yaşama ait nesneler düzenlenişs şekilleriyle tarihsel bir okuma sağlamakla birlikte kitle kültürüne, sosyo-kültürel yoz beğenilere de atıfta bulunmaktadır. Hatta Deniz Şengel'e göre "İzleyiciye tarihsel kimliğin, bütünlüğün ve yüksek kültürün yitişini anımsattıkları için 'hüzün' ve 'keder' veren işlerdir'. ${ }^{24}$

Görüldüğü üzere Karamustafa'nın işlerinde sık kullandığı süsleme ifadesi nesneler sorgulamalarla sanatsal işlev kazanmaktadır. Nilgün Özayten’in deyişiyle; Gülsün Karamustafa'nın bir ölçüde hoşgörülü, kimi zaman yadsıyan, kimi zaman ironik bir bakışla yansıttığı ve toplumu her geçen gün daha fazla etkisine alan bu ürünler arasında evlerdeki dekoratif nesneler ilk sırayı alır. ${ }^{25}$ Ayrıca kırsal kültürün şehir kültürüyle karşıtlıkları ve bu anlamda doğan karma-melez kültürün gündelik hayata sirayet eden nesneleri Karamustafa'nın sanat üretimlerinde içselleştirilmiştir, toplumsal gerçeğe dönüştürülmüştür. Özayten'in anlatımıyla; “Gülsün Karamustafa'nın avantajı, seçtiği nesnelerdeki gerçeklik, yaşamla olan direkt bağlantısıdır. Bu nesne artık düşünceyi iletmek için bir aracı değil, doğrudan düşününün kendisidir’. ${ }^{26}$

\section{Cinsiyet Odaklı İşlerinde Kullanılan Gündelik Nesneler}

Gülsün Karamustafa’nın sanatında temel edindiği göç, kültürel bellek, kimlik, yine bu düzeyde gelişen arabesk izlerinin yanında cinsiyet ve toplumsal cinsiyet üzerine de anlatımlar gündelik nesnelerle yoğun ifadeler oluşturmaktadır. Özellikle Yeni Eğilimler Sergisi'nin son etkinliğinde yer alan ve yıllar sonra "Salt Galata"da da sergilenen Çifte Hakikat (G. 8) yerleştirmesi ve onun oluşum hikâyesi Karamustafa'nın sanata ve nesneye yaklaşım biçimini en iyi anlatan örneklerden birisidir. Çifte Hakikat yerleştirmesindeki cansız mankenin seçilmesi ve onun sergi salonuna taşınma hikâyesi Karamustafa'nın sanat pratiklerini ön plana çıkaran türdendir.

\footnotetext{
“6. Yeni Eğilimler Sergisi (1987) için hazırlık yapan Karamustafa, Beyoğlu Terkos Pasajı'nda karşılaştığı üstünde hamile elbisesi olan tek kollu erkek mankeni satın almak istemiş, ancak mankeni değil de üstündeki hamile elbisesini satmak isteyen esnafla pazarlık sonucu anlaşmış ve erkek mankeni üstündeki elbiseyle satın almıştır. Üzerinde
}

23 Sarığlu, "Gülsün Karamustafa: Sanatçı Kişiliği ve Yapıtları", 21.

24 Deniz Şengel, Düşkün İkona: Gülsün Karamustafa'nın Sanatına Retorik Yaklaşım 1981-1992 (İstanbul: SALT/Garanti Kültür AŞ, 2015), 36. erişim: 8 Eylül 2021. http://saltonline.org/media/files/duskunikona scrd-1.pdf

25 Nilgün Özayten, "Mütevazi Bir Miras-Batı'da Obje Sanatı/ Kavramsal Sanat/ Post-Kavramsal Sanat ve Türkiye'de 1965-1992 Y1lları Arasındaki Benzer Eğilimler" (Doktora Tezi, İstanbul Üniversitesi, 1992), 159.

26 Nilgün Özayten, Mütevazi Bir Miras-Nilgün Özayten Kitabl, 2013 (İstanbul: SALT/Garanti Kültür AŞ, 2013), 151, erişim: 03 Ocak 2019. https://saltonline.org/media/files/nilgun_ozayten_vol1_scrd.pdf 
pembe renk kadın elbisesi ve yüzünde hafif makyajlyla erkek mankenin içinde bulunduğu belirsizliği ve ikili durumu farklı renklerdeki iki demir çerçeve içinde sergilemiş ve çifte hakikati vurgulamıştır. ${ }^{27}$

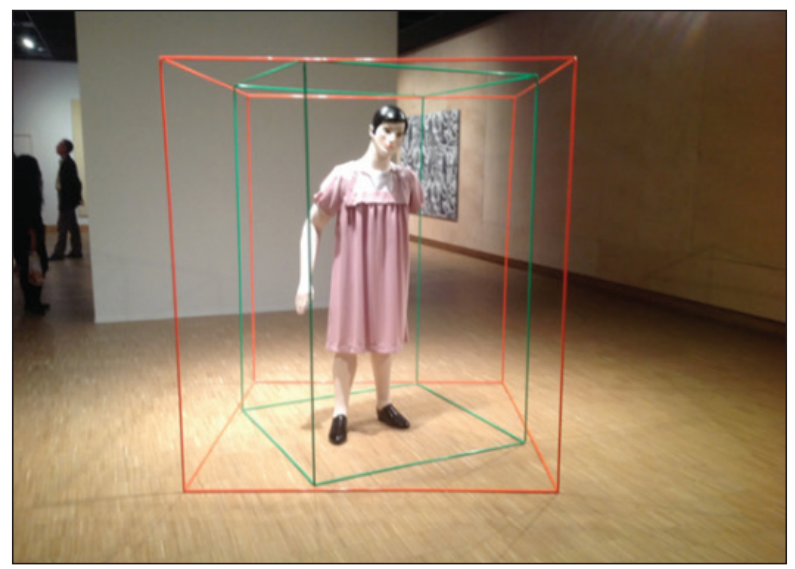

G. 8: Gülsün Karamustafa, Çifte Hakikat, 1987.

(http://www.sanatatak.com/view/saltta-bahar-vadedilmis-bir-sergiyle-devam-ediyor)

1987 yılında düzenlenen 6. Yeni Eğilimler Sergisi'nde ödül alan Çifte Hakikat yerleştirmesi Karamustafa'nın yaşadığı toplumda yaygınlaşan cinsiyet kimliklerinin özeti şeklindedir. Sanatçının cinsiyet yaklaşımları sadece bu çalışmayla sınırlı kalmamış, "Vadedilmiş Bir Sergi" başlı̆̆ı altında Terzi Dikişi, Otel Odası ve Erkek Ağlamaları adlı video yerleştirmeleri ile devam etmiştir. Nitekim 1960'l1 yıllarda dünyada yaygınlaşan feminist etkiler artık Türkiye' de de 1980'lerde baş göstermeye başlamış, kadının statüsü, rolleri ve kimliği her alanda olduğu gibi sanatta da sorgulanma evresine girmiştir. Bu tavrın önemli isimlerinden birisi olan Karamustafa kadının statüsünü, kimliğini ve toplumdaki konumunu ele aldığı nesnelerle içselleştirmiştir.

Bu bağlamda Karamustafa, Türkiye'de 1980'lerde gelişmeye başlayan feminist düşüncenin örneklerini verdiği kadın temelli denilebilecek Klymatlı Gelin, Örtülü Medeniyet gibi resimleri Neworientation, Etiketler gibi yerleştirmeleri ve fotoğraf, video çalışmaları ile ön plana çıkmaktadır. Karamustafa'nın özellikle Neworientation (G. 9) yerleştirmesi kadına dair birçok sorunsalı çarpıcı şekilde dile getirir. Zerrin İren Boynudelik “1986-1996 Tarihleri Arasında İstanbul'da Düzenlenen ve Mekânları İle Doğrudan Illişki Kuran Sergiler” isimli doktora tezinde Neworientation yerleştirmesine dair şöyle bir değerlendirmede bulunmuştur;

"Mekânın çevresi (liman çevresi olarak bilinen Karaköy ve Galata semti) ve bu çevrede mekânın işlevi ile bağlantılı olarak bulunduğu bilinen ve bulunması varsayılan bir başka yaşama biçimine (genelevler ve buradaki hayat kadınları) ve buradaki olası hayatlara

27 İz, "Salt’ta Bahar, 'Vadedilmiş Bir Sergi’yle Devam Ediyor”, (18 Eylül 2013) http://www.sanatatak.com 
(burada çalışan kadınların büyük olasılıkla evlerinden kaçmış kadınlar olacağı varsayımı) bir referans veren işi ile sanatçı mekân ve düzenleme arasında anlam açısından bir ilişki kuruyor ve kavramlarını bu açıdan görselleştiriyor". ${ }^{28}$

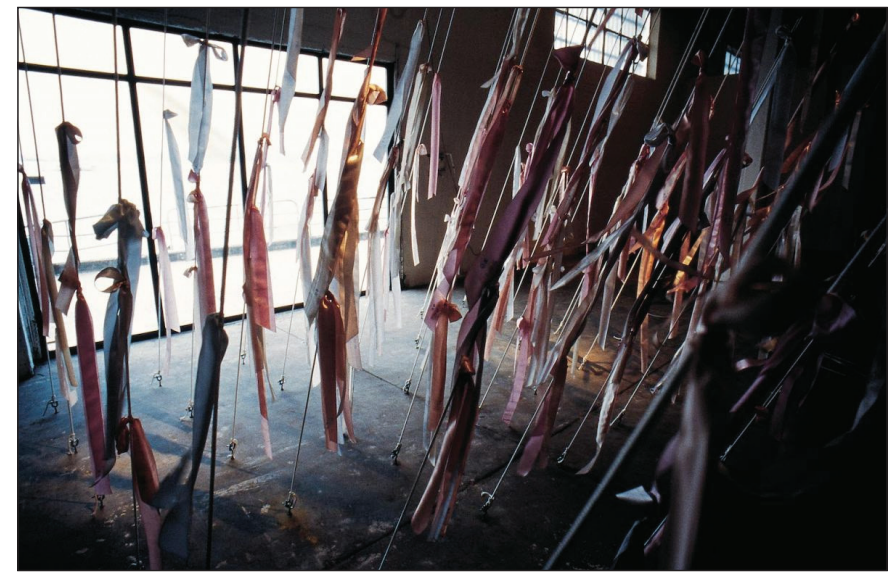

G. 9: Gülsün Karamustafa, Neworientation, 1995, 4. Uluslararas1 İstanbul Bienali, Antrepo, SALT Araştırma, Gülsün Karamustafa Arşivi, (https://blog.saltonline.org/post/171339888759/)

Gülsün Karamustafa, Neworientation yerleştirmesinde anlamsal referanslarını seçtiği kurdele nesnesi ile güçlendirmiştir. Bu çalışmada kurdele; kadının yaşamsal zorluğunu, toplumdaki yer edinme şeklini, evden kaçışını kavramsal hâle getirmiştir. Çalışmada asılan kurdelelerin üstünde kadınların kaybolduğu veya yok olduğu tarihler vardır. $\mathrm{Bu}$ çalışmada kurdele kültürel bir ifade olan dilek ağacına bağlanan kurdeleye de benzetilebilir. Kurdele belki de yitip giden kadınların geri dönmesi, bulunması için bir dilek görevini yüklenmiştir. Dolayısıyla bu yerleştirmede kurdele nesne olmanın ötesinde bellek, tarihsel bir veri ve umut görevini yüklenmiştir.

$\mathrm{Bu}$ bağlamda sanatçı Karamustafa'nın yerleştirmelerinde toplumsal bir bakışın ağırlığı hissedilir. Onun yerleştirmeleri, biçim ve içerikten hareketle işe dâhil edilen nesnelerle bir bütünlük sağlar. Çünkü nesneler bir dönemin, kitlenin ya da tarihsel sürecin anlatımlarıdır.

Genel olarak bakılırsa yaşamın bir anlatımı olan nesne, insana dair çözümleyici bir özelliğe sahiptir. Bu sahiplik, insanların yaşadığı coğrafyaya ait değerleri, kültürel, tarihsel ifadeleri, cinsiyet yaklaşımlarını, kadının ve toplumsal statünün formlarını daha görünür kılmaktadır. Öyle ki nesnenin anlatımsal gücü bir dönemi, onu yaşama şekli hatta kültürel dönüşümü hakkında izler barındırır. Türk sanatının en belirgin yüzlerinden olan Gülsün Karamustafa, nesne temelli yaklaşımlarıyla toplumsal ve kişisel hafızalara yolculuk sağlamaktadır.

28 Zerrin İren Boynudelik, “1986-1996 Tarihleri Arasında İstanbul’da Düzenlenen ve Mekânları İle Doğrudan İlişki Kuran Sergiler”, (Doktora Tezi, İstanbul Teknik Üniversitesi, 1999), 314. 


\section{Sonuç}

Gülsün Karamustafa sıklıkla göç, bellek, kimlik, kültürel öğeler, kitsch-popüler kültür imgeleri, kadının toplumdaki rolü ve toplumsal cinsiyet üzerine çalışmalar yaparak toplumun hafızasına, sosyal ve kültürel tarihine değinmiştir. Karamustafa, seçtiği konuları yaşadığı toplumun ve kendi kişisel tarihinden hareketle kurgulamış, sanatına aktarmıştır. Gülsün Karamustafa'nın sanatındaki en güçlü vurgulardan biri çalışmalarında nesnenin başat rol oynamasıdır. Karamustafa'nın çalışmalarındaki seçtiği nesneler toplumun ruhunu yansıtan, yerelliği içinde barındırmanın yanında ayrıca küresel bir dolaşım sağlayan nesnelerdir.

Enstalasyonlarında nesne vurgusu ağır basan Karamustafa, nesneyi kullanış biçimi kendine has şekilde tezahür eder. Öyle ki onun çalışmalarında yaşam deneyimleri nesneler üzerinden sanat deneyimlerine dönüşmüştür. Sanatçı Karamustafa'da nesne bir dönemi, tarihi, olay ya da travmayı betimler nitelikte olup katmansal görev edinir. Sanatçının işlerinde biçimin ya da içeriğin tek başına ağır basmadığı, ancak nesnenin kendi içindeki kavramsallaştırma olgusunun daha yoğun olduğu söylenebilir. Yani biçim ve içerikle güçlü ağ oluşturan nesne; yaşanan dönemleri, toplumsal bakışları temsil eden, kavramsal ve düşünsel katmanlar sağlamaktadır.

Sanatçının Neworientation, Kuryeler, Mistik Nakliye, Çifte Hakikat ve daha birçok çalışmasında nesne, maddesel gerçeğinden koparılarak başı başına çalışmanın kendisi olmuş ve sanat nesnesine dönüşmüştür.

Karamustafa, Mistik Nakliye yerleştirmesinde kendi toplumundaki göç durumlarını göstergesel bir anlatımla sağlar. Bu eserinde seçtiği saten yorganlar, sergi mekânında tekerlekli metal sepetlerin içerisinde katlanmış şekilde göç etmeye hazır şekilde dururlar. Onun Kuryeler işindeki yeleklerde de yine göçe yönelik bir durumun kodlarını verir. Bu çalışmasında sanatçı, kendi tarihine yönelik bellekleri tazeler niteliktedir ve anneannesinin yaşadıklarını yeleklerin içine diktiği küçük bölmelerle tekrar görselleştirir. Karamustafa'nın Vatan Doğduğun Değil, Doyduğun Yerdir işinde ise sarıp sarmaladığı üç kaşık, göç eden insanların kaçınılmaz gerçeğini temsil etmektedir.

Gülsün Karamustafa, Elvisli Seccade duvar halısı ve Kavanozda Venüs işlerinde ise kültürel imgeler hâline dönüşen figürleri popüler kültür bakışıyla ele alarak kültürel melezlenmenin yansımalarını verir. Özellikle Kavanozda Venüs çalışması Batılı imgenin Doğulu başka bir imgeyle karşılık bulmuş hâlidir. Karamustafa'nın bu işinde sanat imgesi ve mitolojik karakter olan "Venüs" figürünün gündelik nesne olan kavanozun içine yerleşimi kültürel bir bağlamın başka kültürdeki karşılaştırmasını ifade etmektedir. Yani sanatçı bir kültürün yaşamdaki ifadesini başka kültürün imge ve nesneleriyle anlatmıştır. 
Karamustafa, çalışmalarında ayrıca cinsiyet ve toplumsal cinsiyet üzerinden kimlik irdelemeleri yapar. Onun Çifte Hakikat yerleştirmesinde kullandığı kadın elbiseli erkek manken nesnesi bir kimliğin sorgulamasını, cinsiyet üzerine toplumun kalıplaşmış yargılarını ifade eder. Sanatçının Neworientation yerleştirmesi ise kadının esaslı rolünün gerçekleşmeyişinin bir yansımasıdır. Çalışmada yer alan kurdeleler kadının toplumsal statüsünün hatta yaşamının bir kıskacın içine alınışının temsilidir.

Sonuç olarak Gülsün Karamustafa'nın çalışmalarında nesnenin güçlü bir vurgu olduğu neticesine varılmıştır. Karamustafa'nın, çalışmalarında kullandığı gündelik nesneler bir kültürü, hafızayı, toplumsal yaşayış biçimini ortaya koyan analiz aracıdır. Karamustafa'nın işleri popüler kültürün günlük yaşamdaki varlığına, göç, kitsch, kültürel ve kimlik sorgulamalarına, kadınların toplumda yerleşik olan problemlerine dokunur. Onun bu dokunuşları ise nesne odaklı yaklaşımlarla gerçekleşir. Sanatçının kullandığı nesneler bir kültürün, hafızanın kısacası toplumsal yaşayış şeklinin arka planındaki gerçekleri, bakışları ortaya çıkaran bir analiz aracıdır. Gülsün Karamustafa hâlen Türkiye'de, uluslararası platformlarda kuram-düşünce ve pratikleriyle ortak hareket eden ve işlerinde/kullandığı nesnelerde çok katmanlı yelpazeden irdelemeler yapan bir sanatçıdır.

Hakem Değerlendirmesi: Dış bağımsız.

Çıkar Çatışması: Yazarlar çıkar çatışması bildirmemiştir.

Finansal Destek: Yazarlar bu çalışma için finansal destek almadığını beyan etmiştir.

Peer-review: Externally peer-reviewed.

Conflict of Interest: The authors have no conflict of interest to declare.

Grant Support: The authors declared that this study has received no financial support.

\section{Kaynakça/References}

Boynudelik, Zerrin İren. "1986-1996 Tarihleri Arasında İstanbul'da Düzenlenen ve Mekânları İle Doğrudan İlişki Kuran Sergiler”. Doktora tezi, İstanbul Teknik Üniversitesi, 1999.

Çalıkoğlu, Levent. Çağdaş Sanat Konuşmaları 3, 90'lı Yıllarda Türkiye'de Çağdaş Sanat. İstanbul: Yap1 Kredi Yayınları, 2008.

Çelebi Erol, Cansu. “Göçün Öteki Yüzü, Türkiye Çağdaş, Sanatında Göç, Olgusu”. Ulakbilge 47 (2020): 400-407.

“Gülsün Karamustafa ile Salt Araştırma'daki Arşivi Üzerine”. Hazırlayan Sezin Romi. 27 Şubat 2018. Erişim 9 Eylül 2021. https://saltonline.org/tr/2007/gulsun-karamustafa-ile-saltarastirmadaki-arsivi-uzerine

Hasgüler, Solmaz Bunulday. Türkiye’de Sanat Üretimi 1975-2005. İstanbul: Parşömen Yayınc1lık, 2013.

Heinrich, Barbara. Gülsün Karamustafa: Güllerim Tahayyüllerim. İstanbul: Yapı Kredi Kültür Sanat Yayınları, 2007.

İz, M. Kemal. "Salt’ta Bahar, 'Vadedilmiş Bir Sergi'yle Devam Ediyor”. (18 Eylül 2013). Erişim 20 Aralık 2018. http://www.sanatatak.com/view/saltta-bahar-vadedilmis-bir-sergiyle-devam-ediyor. 
Kahraman, Hasan Bülent. Türkiye'de Çağdaş Sanat. İstanbul: Akbank Sanat Yayınları, 2013.

Kaplan, Mehmet Akif. "Çağdaş Türk Sanatında Göç, Yersizyurtsuzlaşma Olgusunun Gülsün Karamustafa Sanat Çalışmaları Üzerinden İncelenmesi” Sosyal Bilimler Dergisi / The Journal of Social Science 29 (2018): 314-324.

Karamustafa, Gülsün. Kuryeler, 1991. Erişim 8 Eylül 2021. https://saltonline.org/tr/664/atolye-ipucu

Karamustafa, Gülsün. “Vatan Doğduğun Değil Doyduğun Yerdir”, Fotoğraf (40x40 cm), Erişim 18 Ocak 2021. https://archives.saltresearch.org/handle/123456789/189732.

Keser, Nimet. Sanat Sözlüğü. İstanbul: Ütopya Yayınevi, 2009.

Kıyar, Neslihan ve Serdar Kul. "Sanat Tanımı Topluluğu ve Bağımsız Bir Çağdaş: Gülsün Karamustafa.” İdil 58 (2019): 783-791.

Özayten, Nilgün. “Mütevazi Bir Miras -Batı'da Obje Sanatı/ Kavramsal Sanat/ Post-Kavramsal Sanat ve Türkiye'de 1965-1992 Yılları Arasındaki Benzer Eğilimler.” Doktora Tezi, İstanbul Üniversitesi, 1992.

Özayten, Nilgün. Mütevazi Bir Miras-Nilgün Özayten Kitabı. İstanbul: SALT/Garanti Kültür AŞ, 2013. Erişim 3 Ocak 2019. https://saltonline.org/tr/546/mutevazi-bir-miras-nilgun-ozayten-kitabi

Sabancılar, Duygu. "Bireysel ve Toplumsal Hafizanın Sanat Eserlerinde Kıyafet Aracılığı ile Kurgulanması Gülsün Karamustafa ve Gülçin Aksoy.” Sanat ve Tasarım Dergisi 18 (2016): 133-145.

Sağır, Çiğdem, “Gülsün Karamustafa”. Seksenlerde Türkiye'de Çağdaş Sanat: Yeni Açılımlar. Ed. İpek Duben ve Esra Yıldız. İstanbul: İstanbul Bilgi Üniversitesi Yayınları, 2008. 158-179. Sağır, Çiğdem. “1980 Sonrası Türkiye’deki Sanatın Dönüşümünde Gülsün Karamustafa'nın Yeri”. Yüksek Lisans Tezi, İstanbul Teknik Üniversitesi, 2005.

Sarıŏglu, Selen. “Gülsün Karamustafa: Sanatçı Kişiliği ve Yapıtları”. Yüksek Lisans Tezi, Mimar Sinan Güzel Sanatlar Üniversitesi, 2007.

Şengel, Deniz. Düşkün İkona: Gülsün Karamustafa'nın Sanatına Retorik Yaklaşım. İstanbul: SALT/ Garanti Kültür AŞ, 2015. Erişim 8 Eylül 2021 http://saltonline.org/media/files/duskunikona_ scrd-1.pdf 
